\title{
REFLEXÕES SOBRE TERRORISMO E DIREITOS HUMANOS: PRÁTICAS E PERSPECTIVAS
}

\author{
Maristela Basso \\ Professora Associada do Departamento de Direito \\ Internacional da Faculdade de Direito da \\ Universidade de São Paulo
}

Resumo:

O terrorismo é concebido tendo em vista a relação entre Direito e Poder, sendo analisado à luz das resoluções da ONU, sob as perspectivas da União Européia e da legislação nacional, motivando novos questionamentos acerca dos direitos humanos e do Direito Penal Internacional.

\section{Abstract:}

The terrorism is conceived according to the relation between Law and Power, analysed towards the light of the ONU's resolutions, in the perspective of the European Union and nacional legislation, causing new questions about the human rights and International Penal Law.

Unitermos: terrorismo; direitos humanos; Direito Penal Internacional.

\section{Direito e poder.}

Reflexões sobre as relações entre "Direito e Poder" são o ponto de partida de nosso estudo, e, de imediato, nos faz lembrar aquela carta que o professor Albert Einstein escreveu para Sigmund Freud, em 1938, na qual indagava a este conhecedor dos corredores da alma humana "o que poderia ser feito para se proteger a Humanidade da maldição da violência, isto é, da guerra". A resposta de Freud pode ser considerada, até mesmo em nossos dias, um texto fundamental para entendermos a relação entre "Direito" e "Poder"

Freud, em sua carta-resposta a Einstein, permitiu-se substituir a palavra "poder" por outra, segundo ele mais "nua e crua": violência. Para Freud é, pois, "um principio geral que os conflitos de interesse entre os homens sejam resolvidos pelo uso da violência. É isto o que se passa em todo o reino animal, do qual o homem não tem motivo por que se excluir"

Certamente, no caso do homem ocorrem também conflitos de "opinião" que podem chegar a atingir as mais raras nuanças da abstração e que acabam por exigir alguma outra técnica para sua solução. Esta é, contudo, uma complicação a mais.

Como é sabido, no início, numa pequena horda humana, era a superioridade da força muscular que decidia quem tinha a posse das coisas, quem fazia 
prevalecer sua vontade, quem dizia o que se podia ou-não fazer. A força muscular foi, paulatinamente, suplementada e substituída pelo uso de instrumentos. $O$ vencedor passou a ser aquele que tinha as melhores armas ou aquele que tinha a maior habilidade no seu manejo. A partir do momento em que as armas foram introduzidas, a superioridade intelectual já começou a substituir a força muscular bruta. Contudo, o objetivo final da luta permanecia o mesmo: uma ou outra facção ou grupo tinha de ser compelido a abandonar suas pretensões por causa do dano que lhe havia sido infligido e pelo desmantelamento de sua força.

Podia-se conseguir esse objetivo de modo mais completo se a violência do vencedor, referida inicialmente no texto de Freud, eliminasse para sempre o adversário, ou seja, se o matasse. As vantagens dessa ação eram duas: o vencido não podia restabelecer sua posição, e seu destino dissuadiria outros de seguirem seu exemplo.

Matar o inimigo, segundo Freud, satisfaz uma (terrível) inclinação natural. No decorrer da história e no transcurso da evolução, o regime da força bruta foi substituído, ainda que não totalmente, pelo império do "Direito" e da "Lei" O caminho que conduziu a essa passagem foi o do reconhecimento do fato de que à força superior de um único indivíduo podía se contrapor a união de diversos indivíduos fracos. A violência podia ser derrotada pela união e o poder daqueles que se uniam: $L$ union fait la force. A Lei, o Direito, passam a ser a força de uma comunidade.

A comunidade deve se manter permanentemente organizada, deve estabelecer regulamentos para evitar riscos de rebelião e deve instituir autoridades para fazer com que esses regulamentos - as Leis - sejam respeitados e para evitar atos de violência.

Não há dúvida de que o reconhecimento de uma comunidade de interesses, como os relatados acima, levou ao surgimento, como afirmou Freud, de vínculos emocionais entre os membros de um grupo de pessoas unidas: sentimentos comuns, que são a verdadeira fonte de sua força.

Como recorda Raymond Aron, "um rápido olhar pela história da raça humana revela uma série infindável de conflitos entre cidades, provincias, raças, religiões, nações, impérios" . As conquistas dos romanos deram aos países próximos ao Mediterrâneo a inestimável Pax romana, e a ambição dos reis franceses de ampliar os seus domínios criou uma França pacífica, unida e pungente.

É um paradoxo o fato de que a guerra pode ser um meio para se conseguir a paz e, ao mesmo tempo, no mais das vezes, seus resultados podem ser de curta duração.

Da Pax romana, à Pax britanica e à Pax americana, o questionamento do professor Einstein parece permancer sem uma resposta definitiva. Por que o Direito e o império da Lei não conseguem evitar a violência? Por que o Direito Internacional (ou "direito das gentes") - com todas suas fontes e instrumentos - ainda não conseguiu afastar a violência do homem, assegurando sua convivência pacífica com outros homens?

Os atentados ocorridos nos EUA, em setembro de 2001, fazem com que não apenas os estudiosos do Direito Internacional, mas todos os homens do nosso 
tempo reflitam acerca dos meios de que a civilização se utiliza para inibir a agressividade que lhe é inata, e como é possível tornar a agressividade inócua ou, talvez, livrar-se dela. Em outras palavras, o que fazer para tornar inofensivo o desejo de agressão que impulsiona a luta da espécie humana pela vida, suas crenças e ideais?

Freud, em seus textos sociais, principalmente em "O mal-estar na civilização" e também no "Muito além do principio do prazer", nos diz que está justamente no que chamamos de "civilização"2 as fontes das grandes frustrações do homem e as razões de sua insatisfação e incompreensões mútuas. Contudo, a civilização consegue dominar o perigoso desejo de agressão do individuo, enfraquecendo-o, desarmando-o, e estabelecendo no seu interior um agente para cuidar dele, como uma guarnição numa cidade conquistada.

Não-obstante isso, o mal-estar e a insatisfação, para a qual as pessoas buscam motivações, permanecem.

Com certeza, o Direito se mais justo -, a Lei - se mais adequada-, e o "teatro da Humanidade", se revisto na sua complexidade, são elementos fundamentais para uma ordem internacional mais justa, na qual os homens encontrem menos fontes de insatisfações e injustiças caldo de cultura em que a violência parece ser a saída mais rápida e o terrorismo a primeira arma.

2. Conceito de terrorismo: breves reflexões.

Se buscarmos a origem da expressão "terrorismo" vamos encontrá-la no latim: terrere (tremer) e deterrere (amedrontar). Assim, fazer tremer e amedrontar são as motivações que fundamentam as ações terroristas.

O professor Celso de Albuquerque Mello nos ensina que o terrorismo implica "técnicas de grupos que contestam o sistema, visando geralmente à mudança de governos, ou é usada por aqueles que pretendem chamar atenção da opinião pública para determinado fato, ou ainda por aqueles que pretendem defender o sistema vigente ${ }^{\prime \prime}$

Apesar de tudo o que já se fez pela paz, parece inevitável a constatação de Berthand de Jouvenel de que "nosso século é aquele da técnica terrorista" e de que o melhor que "os Estados têm a fazer para se proteger é combater a violência através da cooperação internacional" 4 As reflexões de B. de Jouvenel, datadas do século $\mathrm{XX}$, são extremamente oportunas para este que se inicia.

Para Raymond Aron, a "ação terrorista é aquela cujos efeitos psicológicos são desproporcionais aos resultados fisicos" $" 5$

Revisitar algumas definições nos leva a identificar as características do ato terrorista, quais sejam: a. imprevisibilidade; b. arbitrariedade; c. as vítimas não têm

2. Para Freud, a civilização pode ser vista como a "superação do estado primitivo ou bárbaro".

3. In "Direito penal e direito internacional". Rio de Janciro, Frcitas Bastos, 1978.

4. In "De la politique pure". Paris, 1977.

5. In "Paix et guerre entre les nations", Paris, 1962. 
os meios de evitar; d. amoralidade na intenção (não leva em consideração os argumentos humanitários).

Schwarzenberger destaca o fato de que não podemos confundir atos de "guerrilha" com "terrorismo" Segundo ele, "os terroristas atuam, às vezes, individualmente, utilizam a força de modo indiscriminado e excessivo, e os atos terroristas não criam, no mais das vezes, guerras internas" Por outro lado, "guerrilheiros são aqueles que pensam primeiro em termos militares, atuam em grupo e seus atos implicam, quase sempre, em guerras internas" 6

Como se vê, o terrorismo implica ato cruel, que não deixa à vítima ou vítimas possibilidade de defesa ou proteção frente à sua arbitrariedade e imprevisibilidade.

3. Terrorismo: notas sobre seu histórico.

A década de 30 foi importante para que a questão do terrorismo entrasse para a pauta dos temas importantes da ordem jurídica internacional. Dois fatos comoveram a comunidade internacional: os assassinatos do rei Alexandre da Iugoslávia e de Luis Barthon, ministro das Relações Exteriores da França.

A partir destes acontecimentos, o Direito Internacional, como bem demonstrou Geraldo Eulálio do Nascimento e Silva ${ }^{7}$. passou a construir uma nova teia de proteção e prevenção contra atos de terrorismo, e a cooperação internacional passou a ser a palavra de ordem.

Sob esta perspectiva é firmada a Convenção de Genebra, de 1937, para a Prevenção e Repressão do Terrorismo. Nela estão definidos como atos terroristas os atos criminosos dirigidos contra o Estado, os crimes contra a vida, integridade, saúde e liberdade, assim como os fatos internacionais que causam danos públicos, e também fabricar e fornecer armas.

Esta Convenção representou um marco no Direito Internacional contra o terrorismo.

Em 1971, a Organização dos Estados Americanos elaborou a Convenção Para a Prevenção e Repressão de Atos Terroristas, ratificada pelo Brasil, como se verá mais adiante.

Em 1973, já sob os auspícios da ONU, é celebrada a Convenção Para a Prevenção e Repressão do Terrorismo - outro marco fundamental, cuja importância dispensa ulteriores comentários depois do estudo lapidar feito por Luigi Migliorino ${ }^{8}$ nos anos 90.

Em 1976, estimulando também outros países, os EUA promulgaram o Act for the prevention and punishement of crimes against internationally protected persons, o qual prevê pena de vinte anos para quem praticar atos terroristas.

6. In "International law and order", London, 1971.

7. In "Terrorismo e direito internacional", publicado cm "Carta Mcnsal", v. 42, novembro, 1996.

8. "La Dichiarazione delle Nazione Unite Sulle Misure per Eliminare il Terrorismo Internazionale". In Rivista di Diritto Internazionale" 1995. 
Em 1977, o Conselho de Europa, frente o número expressivo de seqüestros de diplomatas, traz novos princípios de repressão ao terrorismo.

4. O terrorismo à luz das resoluções da ONU e sob a perspectiva da União Européia.

Como vimos no item acima, o terrorismo é um fenômeno internacional e as convenções internacionais têm um papel importantíssimo na repressão de atos contra pessoas ou comunidades. É bem verdade que as convenções se deparam sempre com a limitação, que é a necessidade de sua ratificação, para se tornarem obrigatórias nos planos interno e externo.

Neste cenário criado pelas convenções já citadas, a ONU não parou mais de trabalhar contra o terrorismo e a prevenção de seus efeitos. Vejamos algumas das mais importantes resoluções da Assembléia Geral: a. 49/60 - de 9 de dezembro de 1994 - relação de medidas para eliminar o terrorismo internacional; b. $50 / 53$ - de 11 de dezembro de 1995 - reforço e nova relação de medidas para controlar e eliminar o terrorismo; e, c. 50/210 - de 17 de dezembro de 1996 novas medidas.

Somam-se a estas outras resoluções do Conselho de Segurança da ONU que expressam a preocupação internacional ${ }^{9}$

Após os atentados de 11 de setembro de 2001 nos EUA, nọvas resoluções foram proferidas pelo Conselho de Segurança da ONU, ainda mais enfáticas, reforçando os propósitos e princípios da Carta da ONU. Essas novas resoluções reiteram o repúdio ao terrorismo, reafirmam a obrigação dos Estados na prevenção e punição dos atos terroristas e estimulam os Estados no sentido de buscarem um esforço global no combate ao terrorismo ${ }^{10}$

Nesta atmosfera de ação e preocupação da comunidade internacional, os ministros de Justiça da União Européia adotaram, em 6 de dezembro de 2001, uma definição do crime de terrorismo comum aos quinze Estados-membros, na qual terrorismo implica ataque à vida de uma pessoa que pode levar à morte, assim como o ataque à integridade física, seqüestro, tomada de reféns, destruição de instalações públicas, de sistema de transporte, seqüestro de aviões, fabricação ou posse de armas e a ameaça de todos estes atos.

Os quinze Estados-membros irão condenar com pena de quinze anos os crimes mais graves e com oito anos, no mínimo, os outros.

5. Terrorismo: violação dos direitos humanos e dos princípios de Direito Humanitário.

Não resta dúvida, por tudo o que já se disse, que o terrorismo é uma afronta brutal aos direitos humanos e aos princípios de Direito Humanitário. Como se sabe, é um ato amoral.

9. Estamos nos referindo às Resoluçõcs 1.267 e 1.269, ambas de 1999.

10. São as Resoluçõcs: 1368, de 12 de sctembro, de 2001; 1.373, de 28 de sctembro de 2001, c 1.377, de 12 de novembro de 2001. 
Atos terroristas violam, de forma abominável, todos os direitos reconhecidos ao homem na Declaração Universal dos Direitos do Homem, de 1948, que reconhece e consagra o direito à vida, à liberdade e à segurança pessoal $\left(\operatorname{art.~} 3^{\circ}\right)$. Da mesma forma, todo homem tem direito a uma ordem social e internacional na qual possa gozar de seus direitos e liberdades.

O fundamento do ato terrorista, ao fazer tremer e amedrontar, é justamente ir de encontro à ordem internacional que assegura ou procura assegurar a não-violência, o equilíbrio entre pader e Direito e que procura ser uma tela forte em que se assentam e robustecem os direitos humanos e os princípios de valorização da Humanidade.

6. O terrorismo e a legislação brasileira.

Com as preocupações acerca da prevenção e punição do terrorismo, foi promulgado no Brasil o Decreto n. 3.018, de 06 de abril de 1999, no qual os atos de terrorismo são caracterizados e tipificados como delitos contra a vida das pessoas. Esse decreto representa a incorporação no Direito brasileiro da Convenção de Washington, de 1971, celebrada sob os auspícios da OEA, que visa punir e prevenir atos terroristas.

7. Punição e prevenção: perspectivas no Direito Penal Internacional.

As preocupações acerca da punição e prevenção estão também na base do Direito Penal Internacional que mesmo sendo um ramo do Direito Internacional se assenta em sólidas normas do Direito Penal e do Direito Internacional Privado. A modernidade do Direito Penal Internacional faz com que seus princípios e fundamentos cada vez mais se apoiem na cooperação penal internacional.

Nesta óptica, o Tribunal Penal Internacional merece destaque e representa hoje, como demonstra Sylvia Steiner ${ }^{11}$, um aliado promissor contra os atos que violam os princípios humanitários.

Cláudia Perrone-Moysés ${ }^{12}$, em estudo lapidar, nos fala da relação de complementaridade do Tribunal Penal e do conceito de soberania contemporânea, e nos faz refletir acerca da atualidade e vigor do sistema de cooperação penal internacional.

Assim, somente por meio de um esforço em torno de uma forte e consistente cooperação entre Estados poderemos caminhar no sentido de uma concreta prevenção e efetiva punição ao terrorismo.

8. Conclusões: a necessidade de revisão do Direito Internacional.

Não-obstante tudo o que já se disse e se fez no âmbito do Direito Internacional em defesa dos direitos humanos e do fortalecimento dos princípios

11. In "O Tribunal Penal Internacional". Publicado na Revista do Tribunal Regional da 3a. Região, janeiro, 2001.

12. In "O Estatuto do tribunal Penal Internacional e soberania contemporânea". Publicado na Revista Politica Externa, v. 8, maio de 2000. 
humanitários, talvez tenhamos chegado ao momento de conduzir o homem para o centro de nossas atenções e preocupações. Estamos nos referindo aqui ao homem, suas frustrações, necessidades e aspirações.

Como nos ensina Hannah Arendt, "em termos de política, não basta dizer que violência e poder não são, muitas vezes, a mesma coisa" Segundo ela, "poder e violência se opõem; onde um deles domina totalmente, o outro está ausente. $A$ violência aparece onde o poder está em perigo. Resulta do desaparecimento do poder... A violência pode destruir o poder, mas é incapaz de criá-lo..."13

As reflexões de Hannah Arendt nos convidam a relacionar os atentados terroristas recentes à teoria dos sistemas e ao dilema do prisioneiro, isto é, nos impulsionam a continuar pensando naquele diálogo entre Einstein e Freud, com o qual começamos este texto, e no que pode ser feito, por meio de um Direito Internacional mais "humanizado", para proteger a Humanidade do perigoso impulso de agressã̃o.

São Paulo, maio de 2002.

13. In "Crimes da República", São Paulo, 1973. 